\title{
Article \\ Numerical Simulation of Williamson Nanofluid Flow over an Inclined Surface: Keller Box Analysis
}

\author{
Khuram Rafique ${ }^{1}\left(\mathbb{D}\right.$ and Hammad Alotaibi ${ }^{2, *}$ (i) \\ 1 Department of Mathematics, University of Sialkot, Sialkot 51310, Pakistan; khurram.rafique1005@gmail.com \\ 2 Department of Mathematics and Statistics, Faculty of Science, Taif University, P.O. Box 11099, \\ Taif 21944, Saudi Arabia \\ * Correspondence: hm.alotaibi@tu.edu.sa
}

Citation: Rafique, K.; Alotaibi, H. Numerical Simulation of Williamson Nanofluid Flow over an Inclined Surface: Keller Box Analysis. Appl. Sci. 2021, 11, 11523. https://doi.org/ 10.3390/app112311523

Academic Editor: Jianzhong Lin

Received: 10 November 2021 Accepted: 29 November 2021 Published: 5 December 2021

Publisher's Note: MDPI stays neutral with regard to jurisdictional claims in published maps and institutional affiliations.

Copyright: (c) 2021 by the authors. Licensee MDPI, Basel, Switzerland. This article is an open access article distributed under the terms and conditions of the Creative Commons Attribution (CC BY) license (https:// creativecommons.org/licenses/by/ $4.0 /)$.

\begin{abstract}
The study of nanofluids has become a key research area in mathematics, physics, engineering, and materials science. Nowadays, nanofluids are widely used in many industrial applications to improve thermophysical properties such as thermal conductivity, thermal diffusivity, convective heat transfer, and viscosity. This article discusses the effects of heat generation/absorption and chemical reaction on magnetohydrodynamics (MHD) flow of Williamson nanofluid over an inclined stretching surface. The impact of Williamson factor on velocity field is investigated numerically using Keller box analysis (KBA). Suitable similarity transformations are used to recover ordinary differential equations (ODEs) from the boundary flow equations. These ordinary differential equations are addressed numerically. The numerical computations revealed that energy and species exchange decrease with rising values of magnetic field. Moreover, it is found that increasing the chemical reaction parameter increases the Nusselt number and decreases skin friction. Further, the effect of Lewis parameter diminishes energy transport rate. In the same vein, it is also observed that increasing the inclination can enhance skin friction, while the opposite occurred for the energy and species transport rate. As given numerical computations demonstrate, our results are in reasonable agreement with the reported earlier studies.
\end{abstract}

Keywords: KBA; Williamson nanofluid; MHD; heat generation or absorption; inclined surface

\section{Introduction}

In the last few decades, there has been a growing interest in the development of nanotechnology due to its potential to provide a considerable enhancement in heat transmittance and transport properties than base fluids. Such technologies are commonly used in many branches and engineering applications, such as biomedical engineering or medical engineering. In the field of manufacturing mud, nanocomposites stand to create non-porous bag flicks. In medical science, the antibacterial characteristic of nanoparticles enhances its importance for the cure of embroidery bandages. Nanofluid was introduced in the late 1995s by Choi and Eastman [1] to enhance thermal conductivity by using a mixture of a base fluid such as water, ethylene glycol, or oil. Recently, we have seen an explosive growth in activities in such fluids. For example, nanoliquids have significant potential to enhance the efficiency of the solar system due to their superior thermal characteristics. Hayat et al. [2] conducted a numerical study for the rotational effects of nanofluid over the Riga plate. Further, Hayat et al. [3] investigated the expanding sheet for the nanoliquid flow by incorporating Brownian movement and Joule heating impacts. Waqas et al. [4] introduced Brownian diffusion and thermophoretic effects in second grade nanoliquid formulation. Moreover, Khan et al. [5] discussed the formulation of hybrid nanoliquid and analyzed numerical results. Anwar et al. [6] studied the magnetized Williamson nanofluid flow over a slanted sheet. Rafique et al. [7] investigated the Casson nanofluid flow and discussed the influence of slanted angle graphically and numerically. For micropolar nanofluid flow generated by a vertical stretching Riga plate, Alotaibi and Rafique [8] investigated the 
heat and mass transport phenomenon. Other methods that have been proposed based on nanofluid flow by incorporating altered effects can be found in [9-14].

Chemical reactions can be classified into various categories such as single or multiphase reactions, homogenous or heterogeneous reactions, and catalyst or non-catalyst reactions, etc. Generally, the chemical reaction occurs through a chemical process that consists of a number of steps named as primary steps, which make complex the chemical reaction. To decrease the difficulty of the complex chemical reaction, we involve a mathematical model. The mathematical model is used for the chemical process, while computer techniques are employed to elucidate the chemical problems. The study of the chemical reaction is an important part of today's science, to investigate the properties and features of molecules to control, optimize, and simulate the procedure. Nowadays, we can examine activation energy and atomic collisions during the chemical reaction at different stages and observe the microscopic and molecular level of each reaction. Bohra [15] discussed the chemical reaction effect over an inclined sheet numerically. Recently, Rafique et al. [16] scrutinized the chemical reaction effect on the Casson nanofluid flow over an inclined sheet. By considering higher-order chemical reactions with heat source (sink) impacts, Alotaibi and Eid [17] performed a numerical investigation on the Darcy-Forcheimer's three-dimensional (3D) nanofluid flow with a heated porous surface and the influence of an external magnetic field and nonlinear radiation. Numerous investigators considered the chemical reaction effect on different fluids flows with different geometries [18-20].

In the last two decades, there has been an effort to address various types of the flow of non-Newtonian liquids due to their interesting and utilitarian aspects in various fields, especially technology, structures, and geophysics. Scientists and engineers are exploring different methods to identify the structures of rheological fluids and their complex behavior. An example of these non-Newtonian liquids is a pseudoplastic liquid, which is one of the most fascinating liquids due to its large number of applications in engineering and industrial processes [21]. However, the challenge is to explore the behavior of such liquids. For this scenario, the Williamson liquid model [22] was introduced to efficiently capture the desired behavior. Investigations on the flow characteristics of Williamson nanofluid by considering changed geometries have been given in detail by [23-28]. A more detailed discussion is given in some related works (see, for example, [29-32]).

To our knowledge, no investigation so far has been devoted to studying Williamson nanofluid flow towards an inclined stretching surface considering chemical reaction and Brownian motion effects. So, to fill this gap in the literature, we conducted this study, which can also support the study of brain tumors and breast cancer. Therefore, inspired by the Keller box scheme used by Nazar et al. [33], this article employs such a scheme to investigate Williamson nanofluid flow over an inclined stretching surface in the presence of chemical reaction and Brownian motion effects. The effects of the different physical parameters of practical interest on temperature, velocity, and concentration contours are examined numerically and are presented through graphs.

\section{Mathematical Formulation}

This section analyzes the flow behavior of Williamson nanofluid on an inclined surface. The angle $\Omega$ is considered among stretching sheet and vertical direction. A further sheet stretched with the rate $/ \mathrm{Cl}$ causes the flow of fluid. Heat generation or absorption impacts are under consideration. The concentration and wall temperature are taken as $T_{w}, C_{w}$, respectively, while $u_{w}$ denotes the velocity on the wall. Moreover, at $y$ approaches to infinity $T_{\infty}, C_{\infty}$ exhibits temperature and nanoparticles concentration, as shown in Figure 1. Additionally, Figure 1 presents the flow model and coordinate scheme. For Williamson fluid, the expression for Cauchy stress tensor is given as [34]:

$$
\begin{gathered}
S=-p I+\tau \\
\tau=\left[\mu_{\infty}+\frac{\left(\mu_{0}-\mu_{\infty}\right)}{1-\Gamma \gamma^{*}}\right] A_{1},
\end{gathered}
$$


where $\tau$ denotes extra stress tensor, limiting viscosity at zero shear rate is $\mu_{0}$ and at infinite shear rate is $\mu_{\infty}, \Gamma>0$ signifies time constant, and $A_{1}$ denotes the first Rivlin-Erickson tensor.

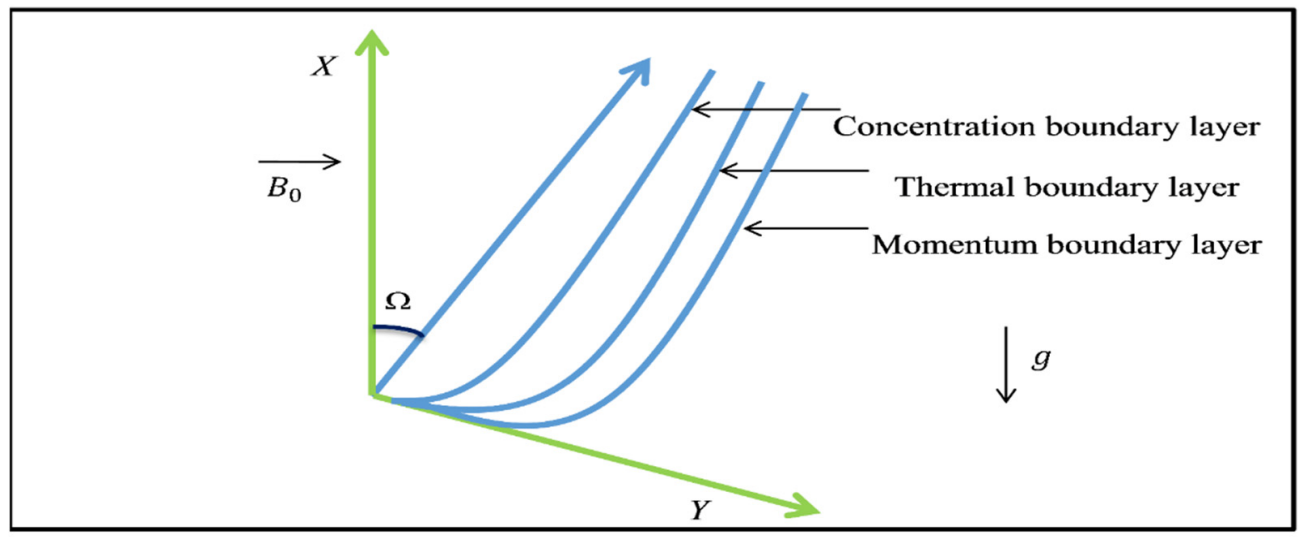

Figure 1. Physical structure with coordinates.

From [34], we obtain

$$
\tau=\mu_{0}\left[1+\Gamma \gamma^{*}\right] A_{1}
$$

The mathematical model for this flow is [35]

$$
\begin{gathered}
\frac{\partial u}{\partial x}+\frac{\partial v}{\partial y}=0 \\
u \frac{\partial u}{\partial x}+v \frac{\partial u}{\partial y}=v \frac{\partial^{2} u}{\partial y^{2}}+\sqrt{2} v \Gamma \frac{\partial u}{\partial y} \frac{\partial^{2} u}{\partial y^{2}}+g\left[\beta_{t}\left(T-T_{\infty}\right)-\beta_{c}\left(C-C_{\infty}\right)\right] \cos \Omega-\frac{\sigma B_{0}^{2}}{\rho} u \\
u \frac{\partial T}{\partial x}+v \frac{\partial T}{\partial y}=\alpha \frac{\partial^{2} T}{\partial y^{2}}+\tau\left[D_{B} \frac{\partial C}{\partial y} \frac{\partial T}{\partial y}+\frac{D_{T}}{T_{\infty}}\left(\frac{\partial T}{\partial y}\right)^{2}\right]+\frac{Q_{0}}{\rho C_{p}}\left(T-T_{\infty}\right) \\
u \frac{\partial C}{\partial x}+v \frac{\partial C}{\partial y}=D_{B} \frac{\partial^{2} C}{\partial y^{2}}+\frac{D_{T}}{T_{\infty}} \frac{\partial^{2} T}{\partial y^{2}}-R^{*}\left(C-C_{\infty}\right) .
\end{gathered}
$$

Let us consider the conditions as

$$
\begin{gathered}
u=u_{w}(x)=c x, v=0, T=T_{w}, C=C_{w} \text { at } y=0, \\
u \rightarrow u_{\infty}(x)=0, v \rightarrow 0, T \rightarrow T_{\infty}, C \rightarrow C_{\infty} \text { as } y \rightarrow \infty .
\end{gathered}
$$

The stream function is given as

$$
u=\frac{\partial \psi}{\partial y}, v=-\frac{\partial \psi}{\partial x}
$$

using appropriate similarity transformations such as

$$
\begin{gathered}
u=c x f(\eta), v=-\sqrt{c v} f(\eta), \eta=y \sqrt{\frac{c}{v}} \\
\theta(\eta)=\frac{T-T_{\infty}}{T_{w}-T_{\infty}}, \phi(\eta)=\frac{C-C_{\infty}}{C_{w}-C_{\infty}} .
\end{gathered}
$$

On substituting Equation (10), the system of Equations (4)-(7) converted to

$$
\begin{gathered}
f^{\prime \prime \prime}+f f^{\prime \prime}-f^{\prime 2}+\gamma_{1} f^{\prime \prime} f^{\prime \prime \prime}+\left(G r_{x} \theta+G c_{x} \phi\right) \cos \Omega-M f^{\prime}=0, \\
\left(\frac{1}{\operatorname{Pr}}\right) \theta^{\prime \prime}+f \theta^{\prime}+\lambda_{1} \theta+N b \phi^{\prime} \theta^{\prime}+N t \theta^{\prime 2}=0, \\
\phi^{\prime \prime}+\operatorname{Lef}^{\prime}+N t_{b} \theta^{\prime}-L e R \phi=0,
\end{gathered}
$$


where

$$
\begin{gathered}
M=\frac{\sigma B_{0}^{2}}{a \rho}, N t=\frac{\tau D_{T}\left(T_{w}-T_{\infty}\right)}{v T_{\infty}}, G r_{x}=\frac{g \beta_{t}\left(T_{w}-T_{\infty}\right) x^{-1}}{a^{2}}, \operatorname{Re}_{x}=\frac{u_{w}(x) x}{v}, \\
G c_{x}=\frac{g \beta_{c}\left(C_{w}-C_{\infty}\right) x^{-1}}{a^{2}}, N t_{b}=\frac{N t}{N b}, \lambda_{1}=\frac{Q_{0}}{a \rho C_{p}}, \gamma_{1}=\Gamma x \sqrt{\frac{2 c^{3}}{v}}, N b=\frac{\tau D_{B}\left(C_{w}-C_{\infty}\right)}{v}, \\
R=\frac{R^{*}}{a} .
\end{gathered}
$$

To find similarity solution, $G r_{x}$ and $G c_{x}$ should be independent of $x$. Hence, suppose that $[36,37]$

$$
\beta_{t}=n x^{1}, \beta_{c}=n_{1} x^{1},
$$

where $n_{1}$ and $n$ denote constants. Replacing Equation (15) into the parameters $G r_{x}$ and, $G c_{x}$ we obtain

$$
G c=\frac{g n_{1}\left(C_{w}-C_{\infty}\right)}{a^{2}}, G r=\frac{g n\left(T_{w}-T_{\infty}\right)}{a^{2}} .
$$

Equation (8) is converted to

$$
\begin{gathered}
f(\eta)=0, f^{\prime}(\eta)=1, \theta(\eta)=1, \phi(\eta)=1, \text { at } \eta=0, \\
f^{\prime}(\eta) \rightarrow 0, \theta(\eta) \rightarrow 0, \phi(\eta) \rightarrow 0, \text { at } \eta \rightarrow \infty .
\end{gathered}
$$

The physical parameters are defined as:

$C_{f}=\frac{\tau_{w}}{\rho u_{w}^{2}}$ is the skin-friction;

$N u=\frac{x q_{w}}{k\left(T_{w}-T_{\infty}\right)}$ is the Nusselt number;

$S h=\frac{x q_{m}}{D_{B}\left(C_{w}-C_{\infty}\right)}$ is the Sherwood number,

where

$$
\begin{aligned}
q_{m} & =-D_{B} \frac{\partial C}{\partial y}, \\
q_{w} & =-k \frac{\partial T}{\partial y}, \\
\tau_{w} & =\mu\left[\frac{\partial u}{\partial y}+\frac{\Gamma}{2}\left(\frac{\partial u}{\partial y}\right)^{2}\right] \text { at } y=0 .
\end{aligned}
$$

The related expressions of $-\theta^{\prime}(0),-\phi^{\prime}(0)$ and $C_{f x}$ are defined as

$$
-\theta \prime(0)=\frac{N u_{x}}{\sqrt{\operatorname{Re}_{x}}},-\phi^{\prime}(0)=\frac{S h_{x}}{\sqrt{\operatorname{Re}_{x}}}, C_{f x} \sqrt{\operatorname{Re}_{x}}=f^{\prime \prime}(0)+\frac{\gamma_{1}}{2} f^{\prime \prime}(0) .
$$

\section{Results and Discussion}

This section presents numerical simulations of non-Newtonian liquid called Williamson nano fluid over a slanted surface. The heat generation or absorption effects are incorporated in the energy equation, while the chemical reaction is added in mass transport equation. The converted differential equations by the utilization of supported similarity transformation are solved numerically using the Keller box method. The effects of pertinent flow factors, i.e., chemical reaction effect $R$ Brownian motion factor $N b$, magnetic factor $M$, local Grashof number $G r, G c$ local modified Grashof number, inclination, i.e., $\Omega$, Pr, i.e., Prandtl number, thermophoresis assumed by $N t$, heat generation or absorption factor $\lambda_{1}$, Williamson factor $\gamma_{1}, R$ (chemical reaction), and Lewis number $L e$, are presented via several diagrams and tables to show their impacts on velocity, temperature, and concentration distributions. In addition, physical descriptions of the involved effects in this study are presented.

Figure 2 exhibits that dimensionless velocity is moderated by resistive force, which is produced by the magnetic effect. It is verified that the numerical computations of $f^{\prime}(\eta)$ for $G r$ and $G c$, which are displayed in Figures 3 and 4, show a good approval with the reported earlier study by Rafique et al. [38]. It is true because the buoyancy effect increases the speed of fluid flow. Figure 5 reveals the inclination impact on the velocity. It is clear that $f^{\prime}(\eta)$ decreases on growing angle, and the recovered trend is in reasonable agreement with finding by Ramesh et al. [39]. Physically, when $\Omega=90^{\circ}$, the buoyancy force effect 
declines; as a result, velocity also decreases. Figure 6 demonstrates that the Williamson factor decreases the velocity field because the boundary layer thickness decreases with growth in non-Newtonian Williamson parameter.

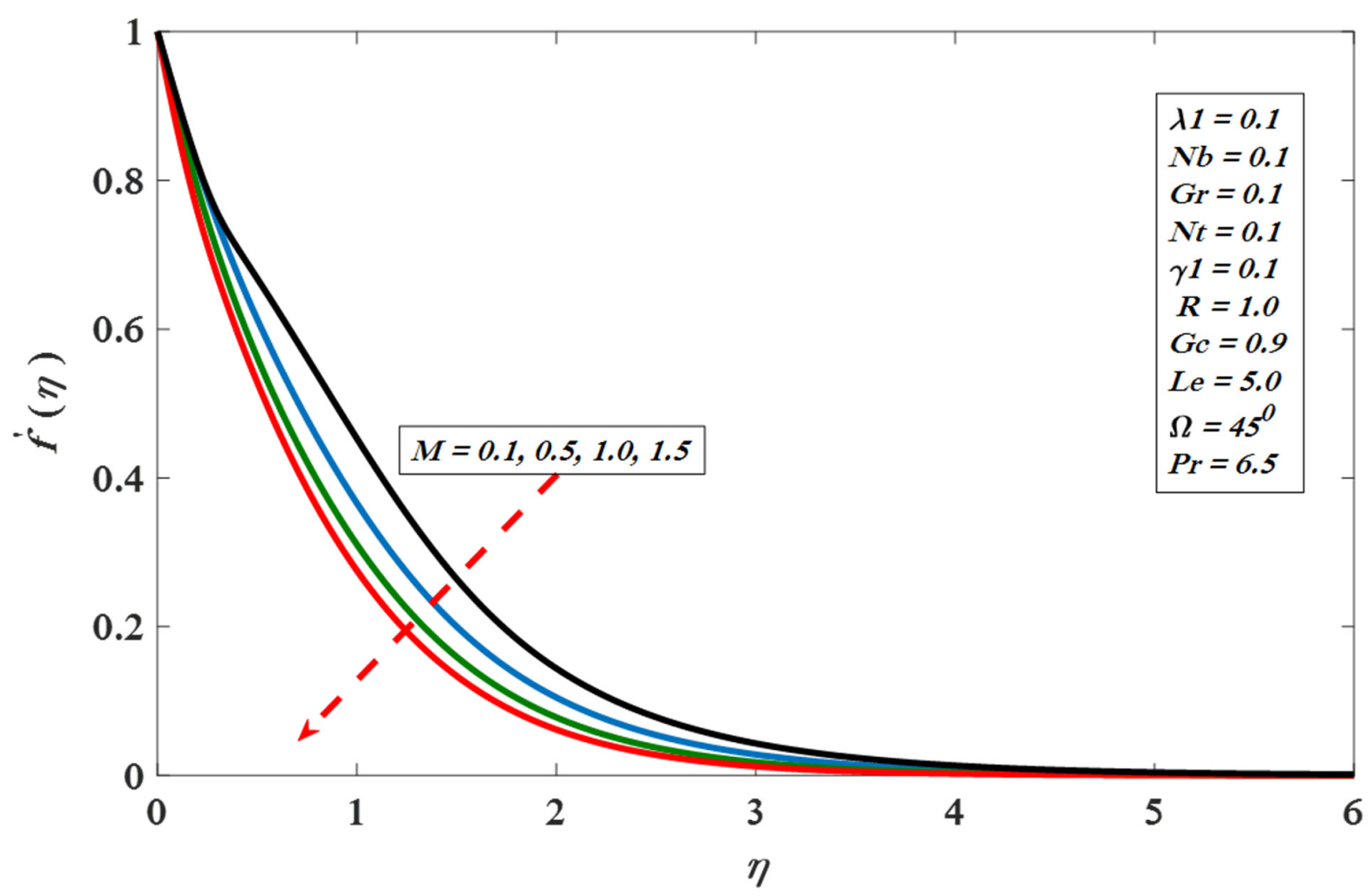

Figure 2. Velocity profile versus $M$.

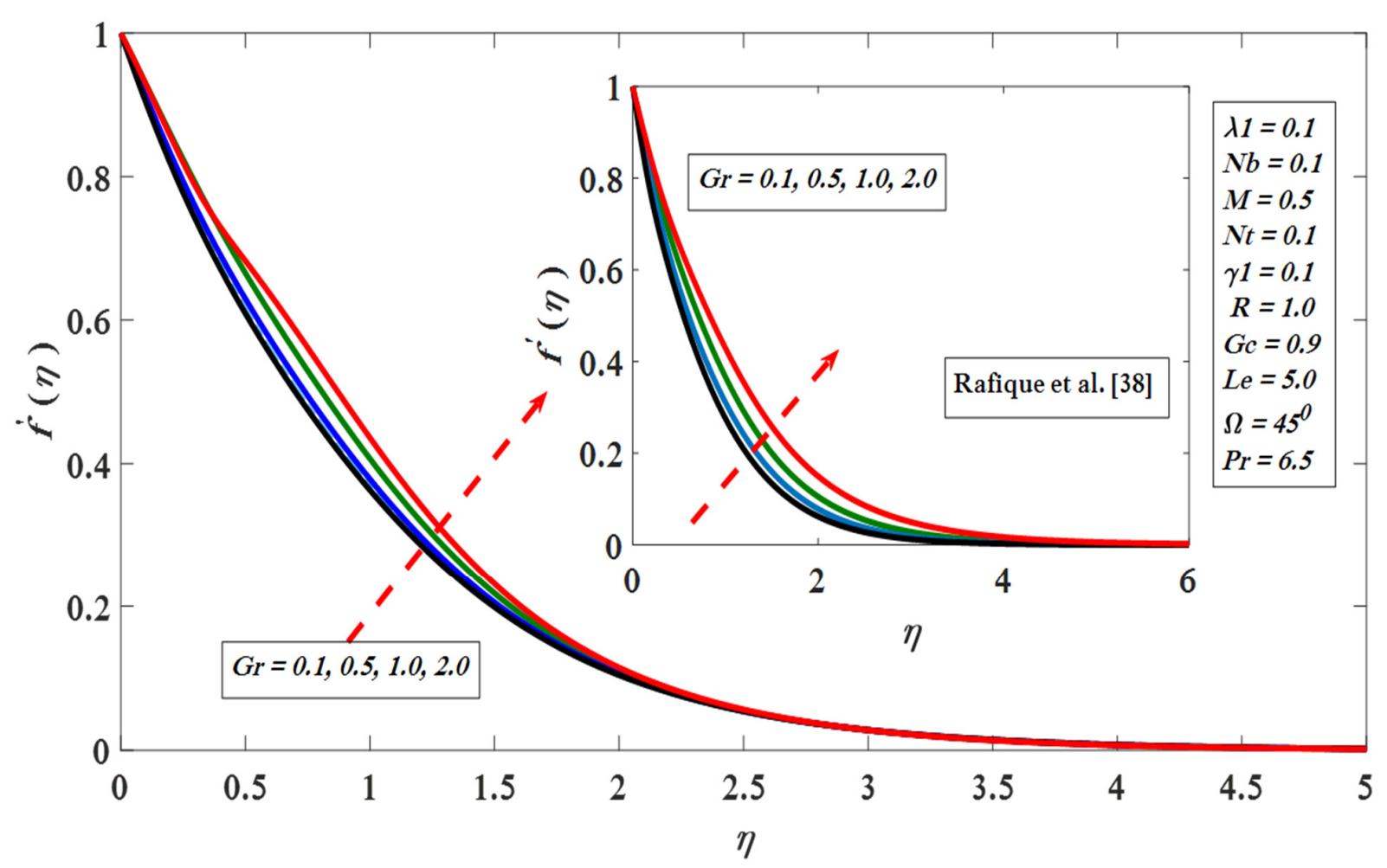

Figure 3. Velocity profile versus Gr. 


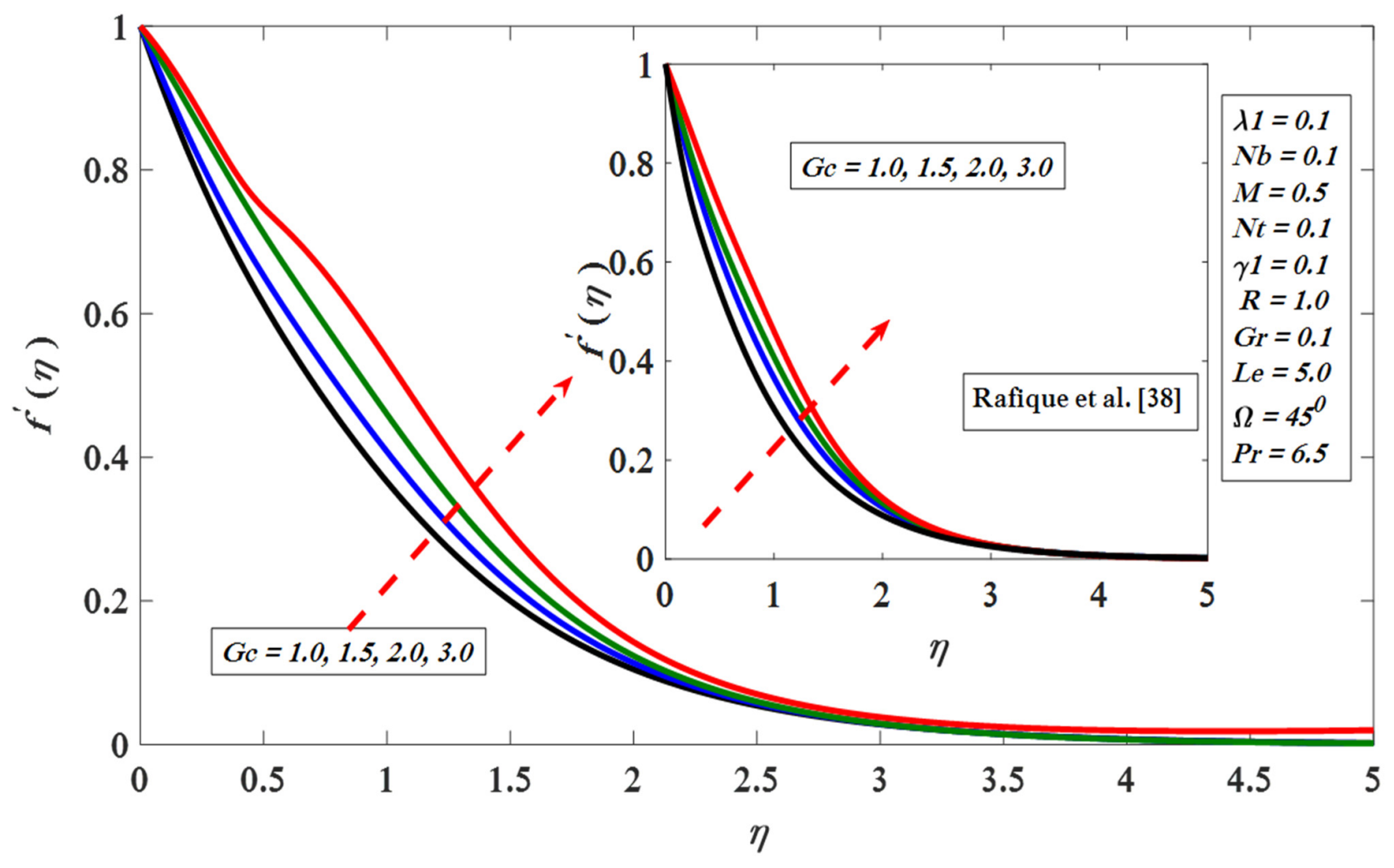

Figure 4. Velocity profile versus Gc.

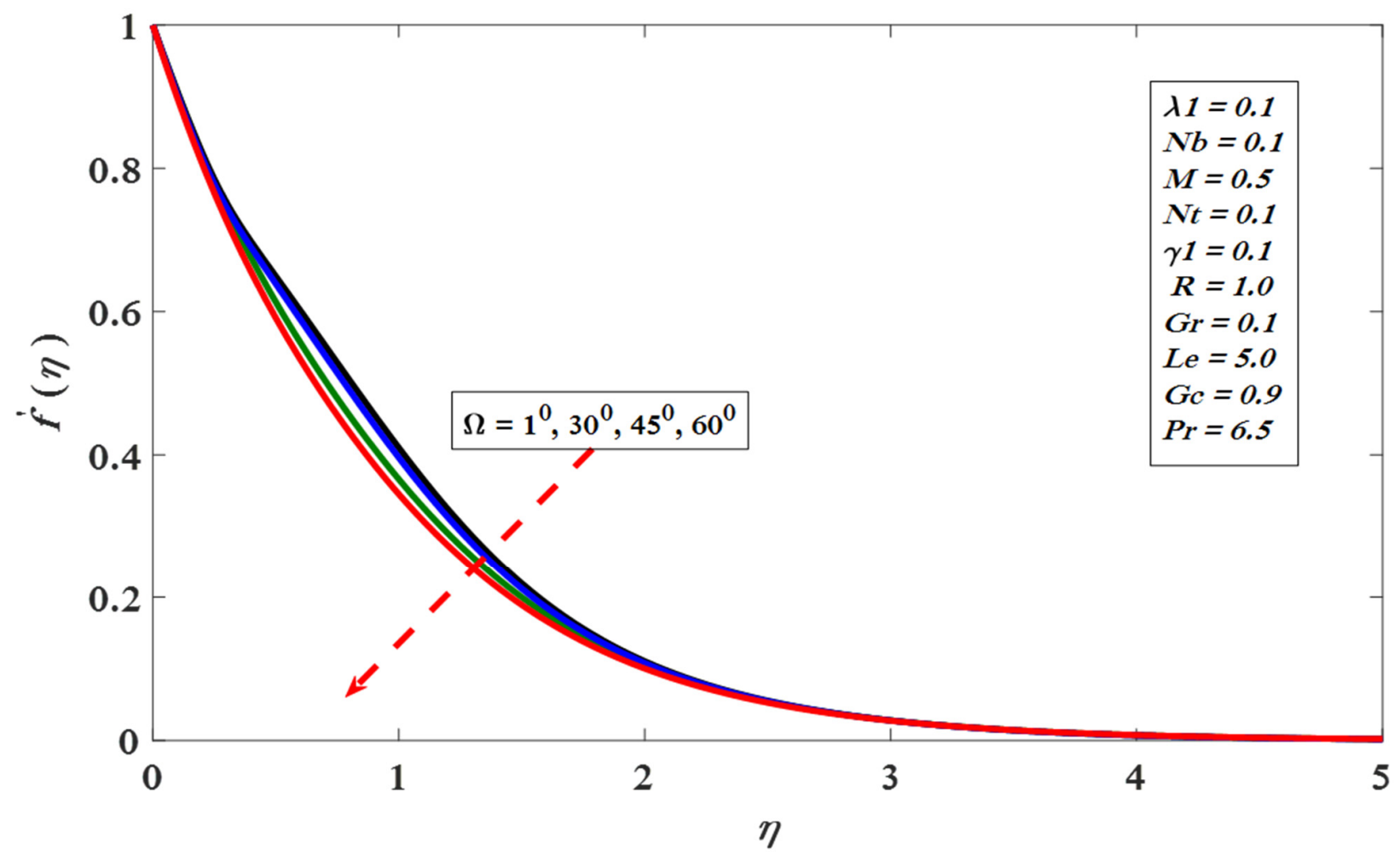

Figure 5. Velocity profile versus $\Omega$. 


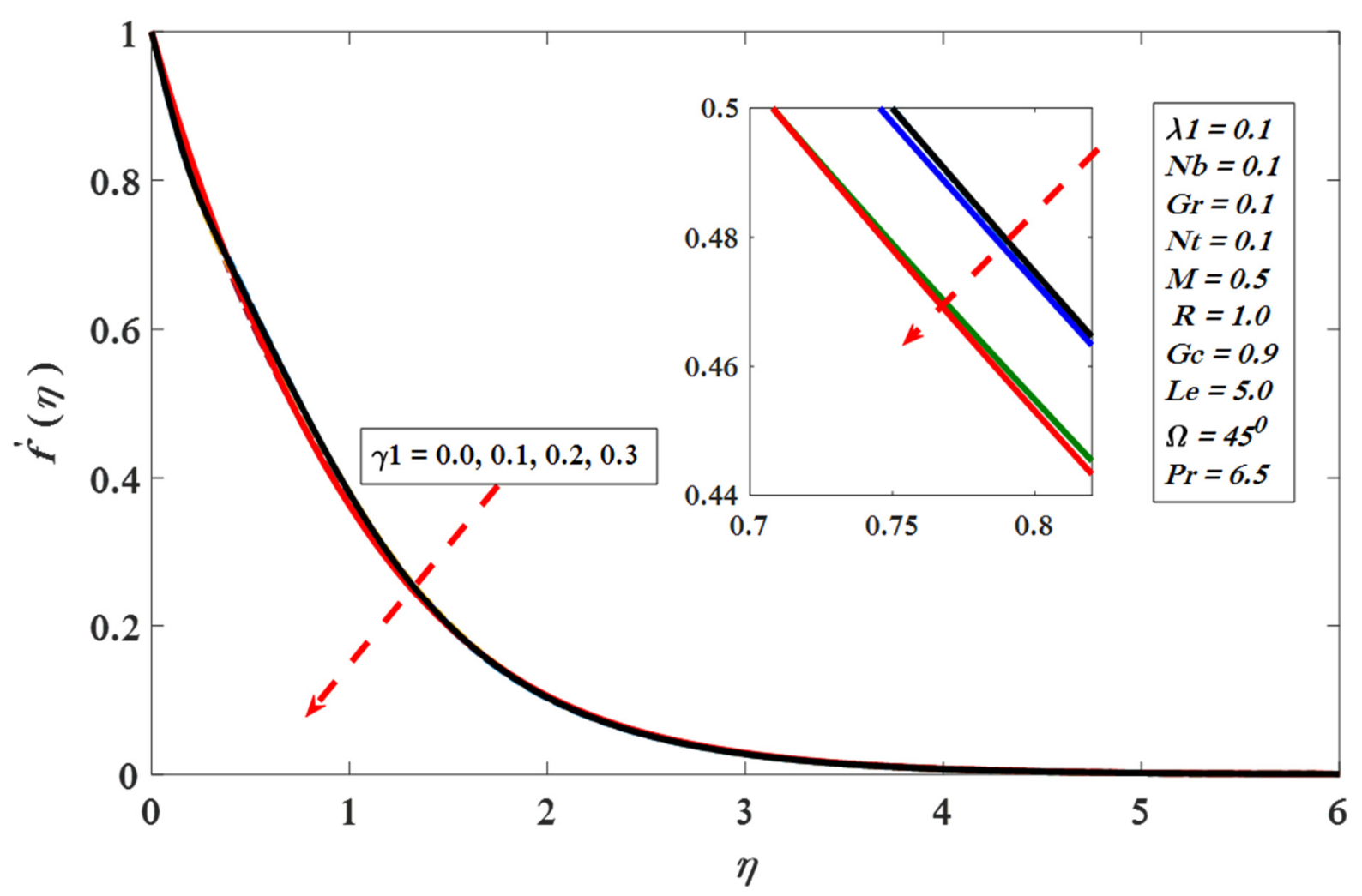

Figure 6. Velocity profile versus $\gamma_{1}$

The magnetic field increases the temperature profile in Figure 7. Figure 8 portrays temperature increases with respect to $\lambda_{1}$, i.e., heat generation or absorption factor generates heat in the flow field and temperature enhances with in the thermal boundary layer. Figure 9 shows an enhancement in $\mathrm{Pr}$ basis the viscosity enrichment and descent in thickness of thermal boundary layer, finally temperature decreases. The irregular diffusion of particles warms up the boundary layer, because of which the temperature of the fluid increases as shown in Figure 10. Figure 11 exhibits temperature increases against thermophoretic effects. Increasing values of thermophoresis imply a higher shear gradient and temperature difference. Therefore, changes in the thermophoresis parameter help us to improve the temperature difference across the boundary layer.

Figure 12 demonstrates that the concentration outline increases as we strengthen the magnetic field. A similar impact on the temperature profile against the magnetic parameter was observed by Ullah et al. [40]. Further, Figure 13 reveals that $\phi(\eta)$ displays a converse relation with $R$ (chemical reaction). It is notable that, with change in chemical reaction, Salleh et al.'s [41] results have been recovered. Figure 14 displays the boundary layer viscosity changes by enhancing Lewis number. A larger Lewis number is related to a lower $D_{B}$ and vice versa. The boundary layer thickness decreases when $\mathrm{Nb}$ increases, which causes a decline in concentration distribution (see Figure 15). Figure 16 presents the thermophoresis influence on $\phi(\eta)$, showing direct correspondence with $N t$, because nanoparticle concentration is a strong function of $N t$, due to which $\phi(\eta)$ was significantly affected. Further, large values of $\phi(\eta)$ indicate that stronger $N t$ increases the thermal conductivity of nanoparticles adjacent to the wall. 


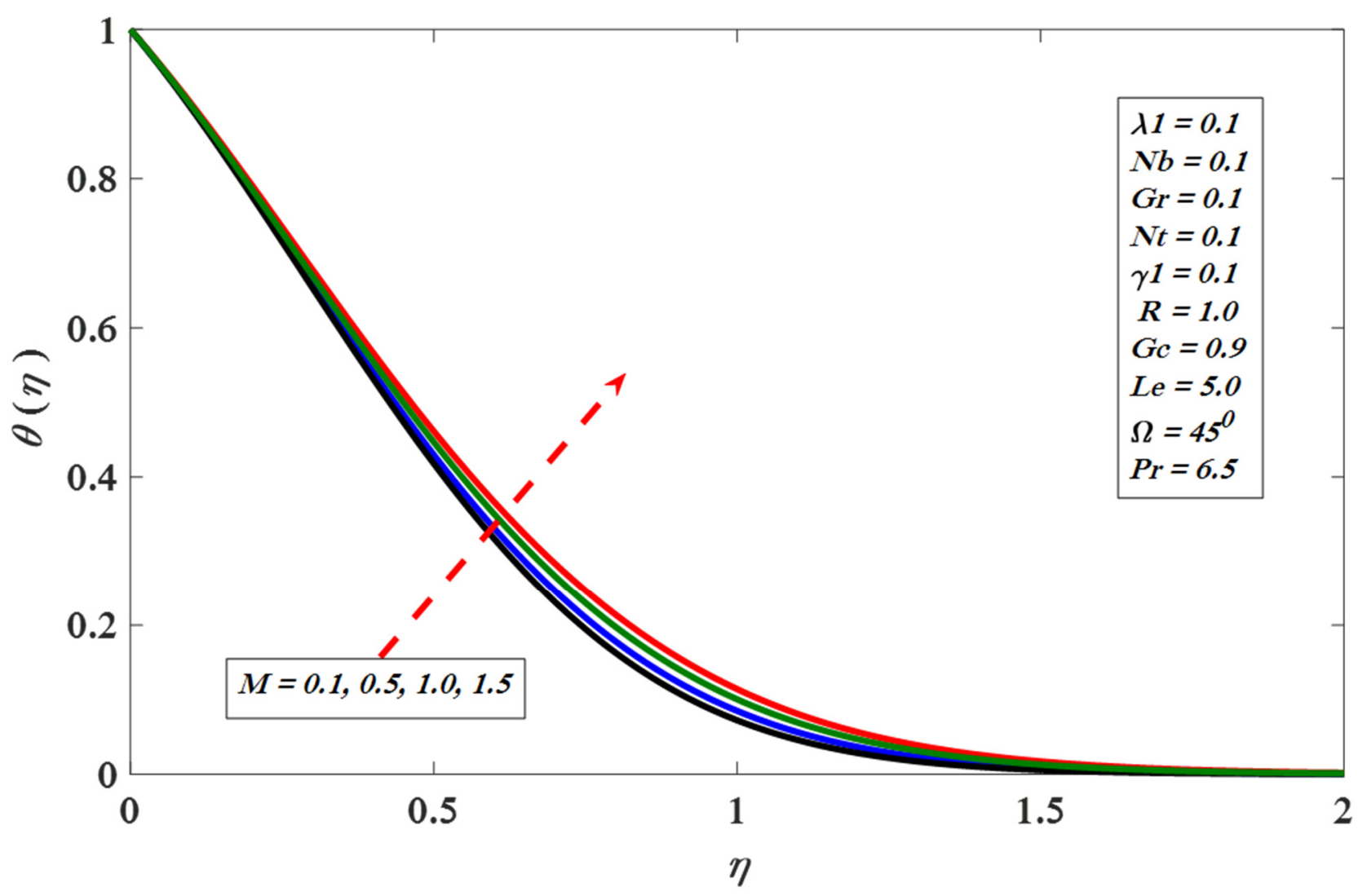

Figure 7. Temperature profile versus $M$.

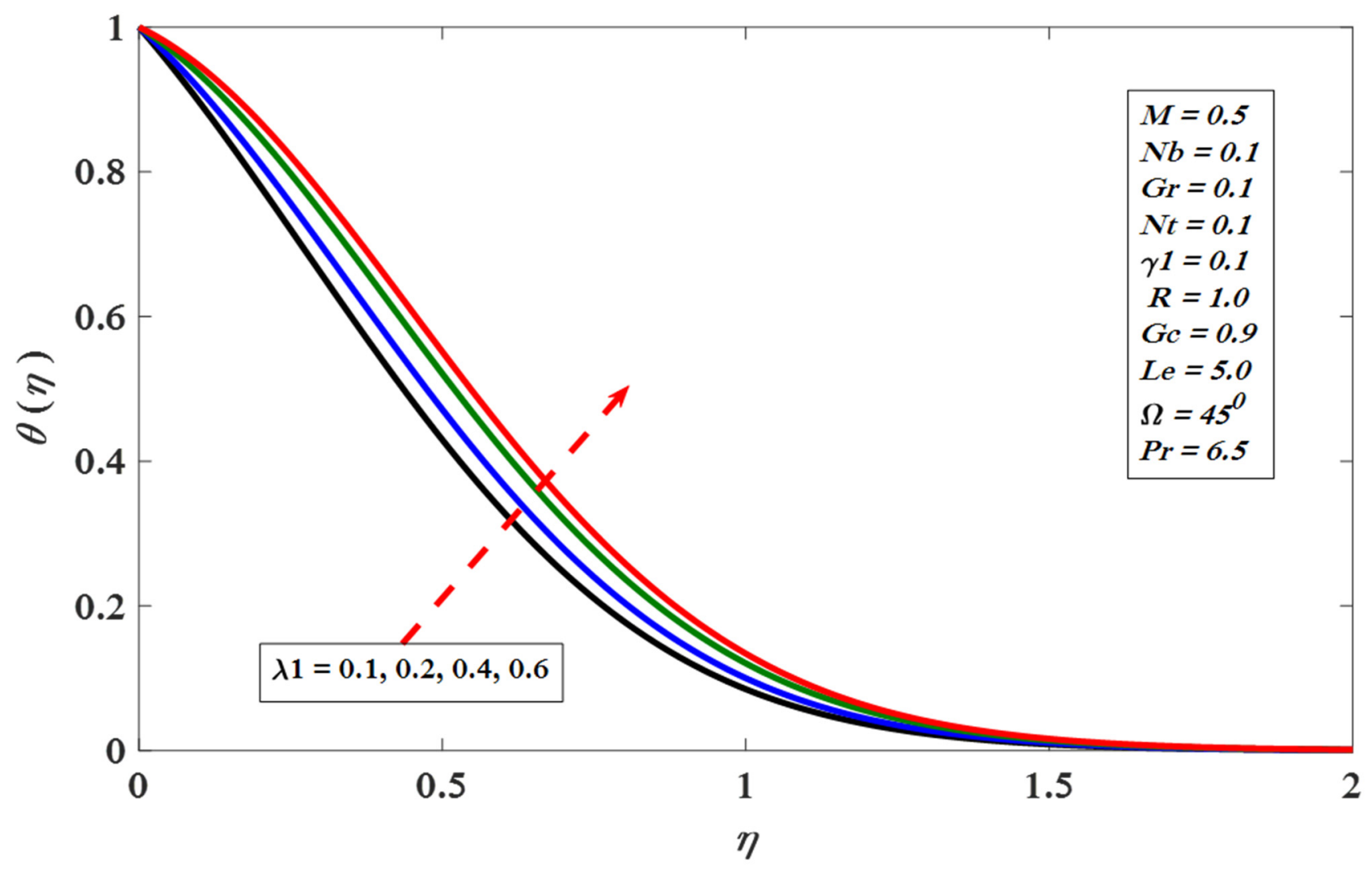

Figure 8. Temperature profile versus $\lambda_{1}$ 


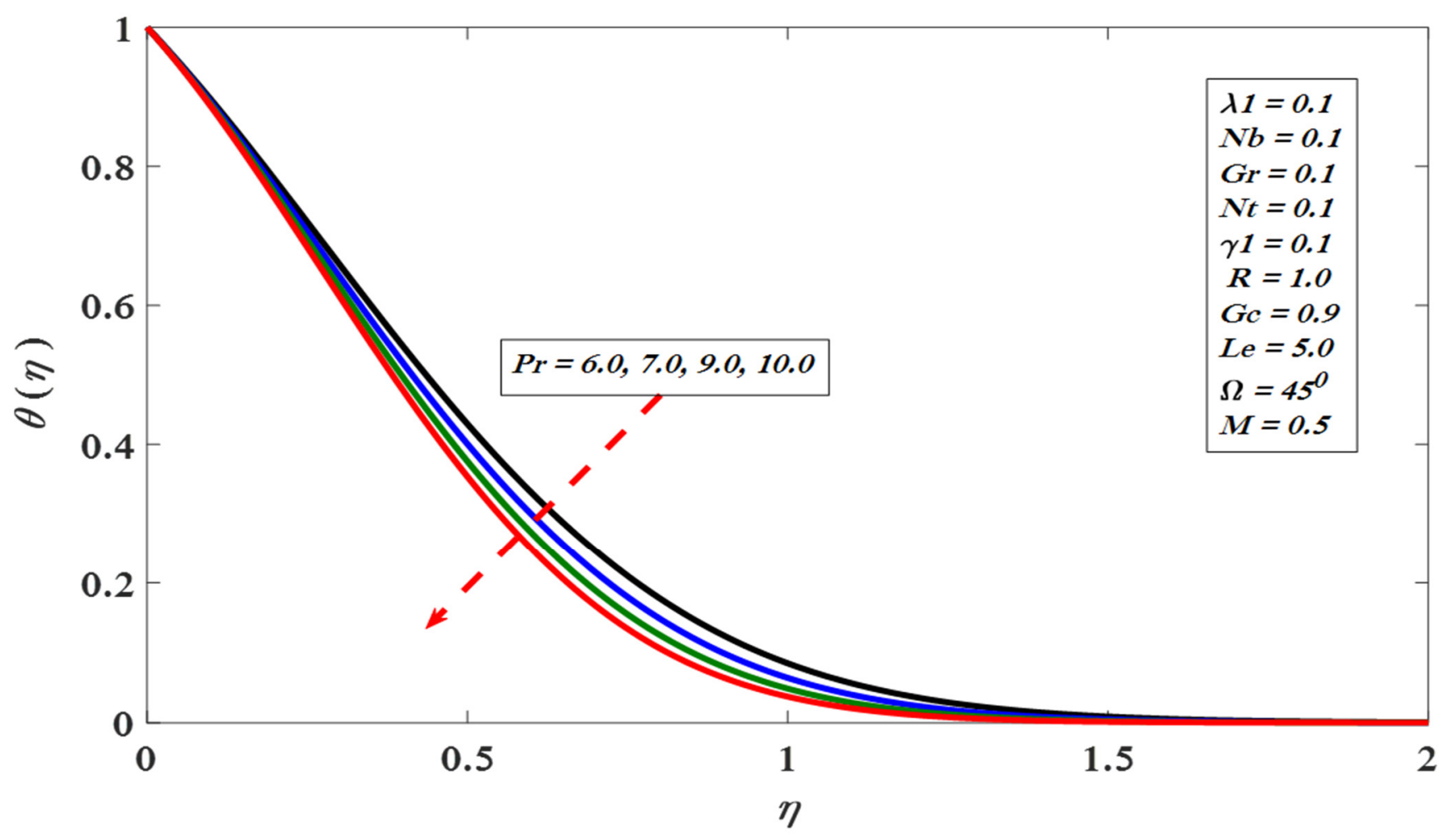

Figure 9. Temperature profile versus Pr.

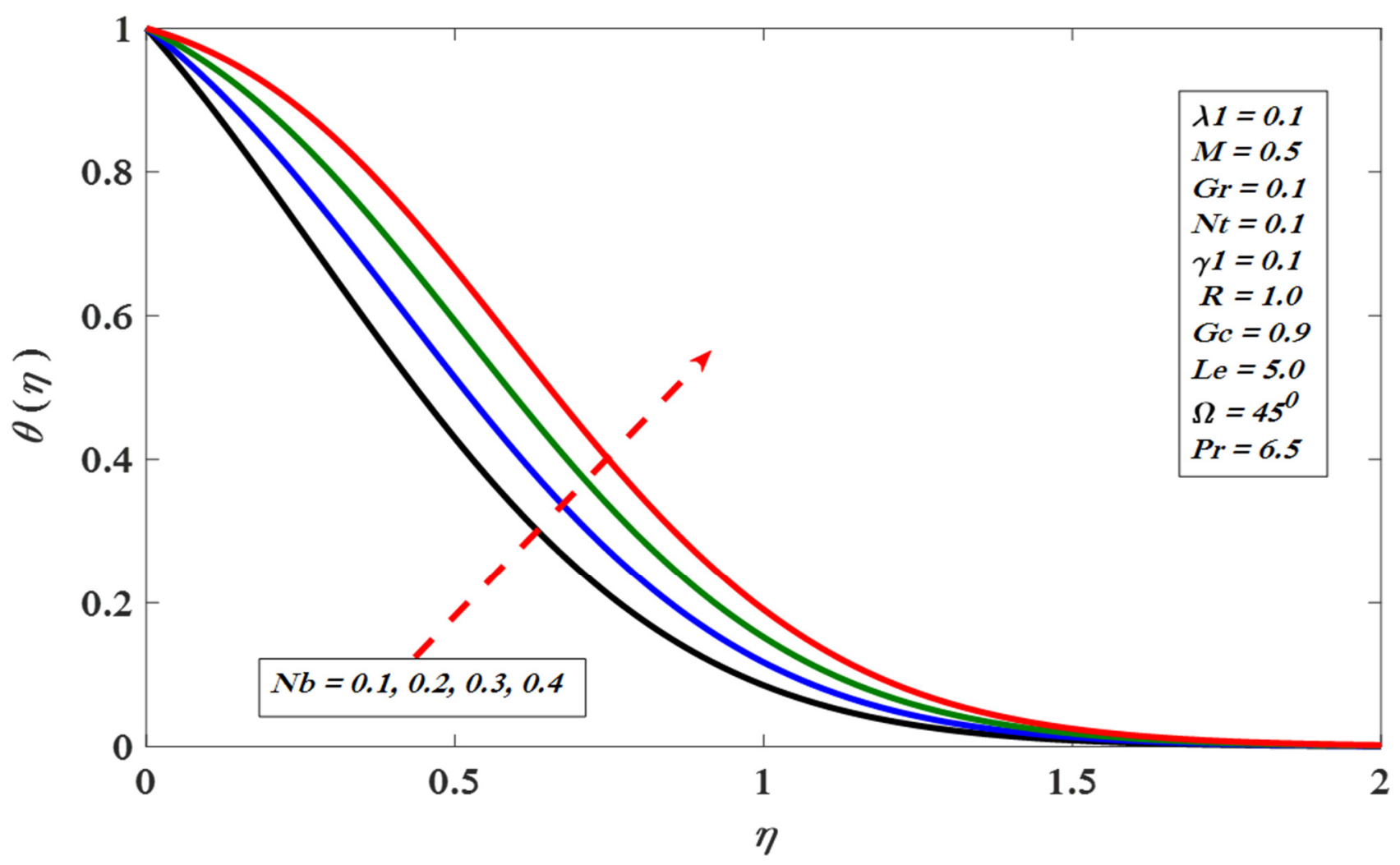

Figure 10. Temperature profile versus $N b$. 


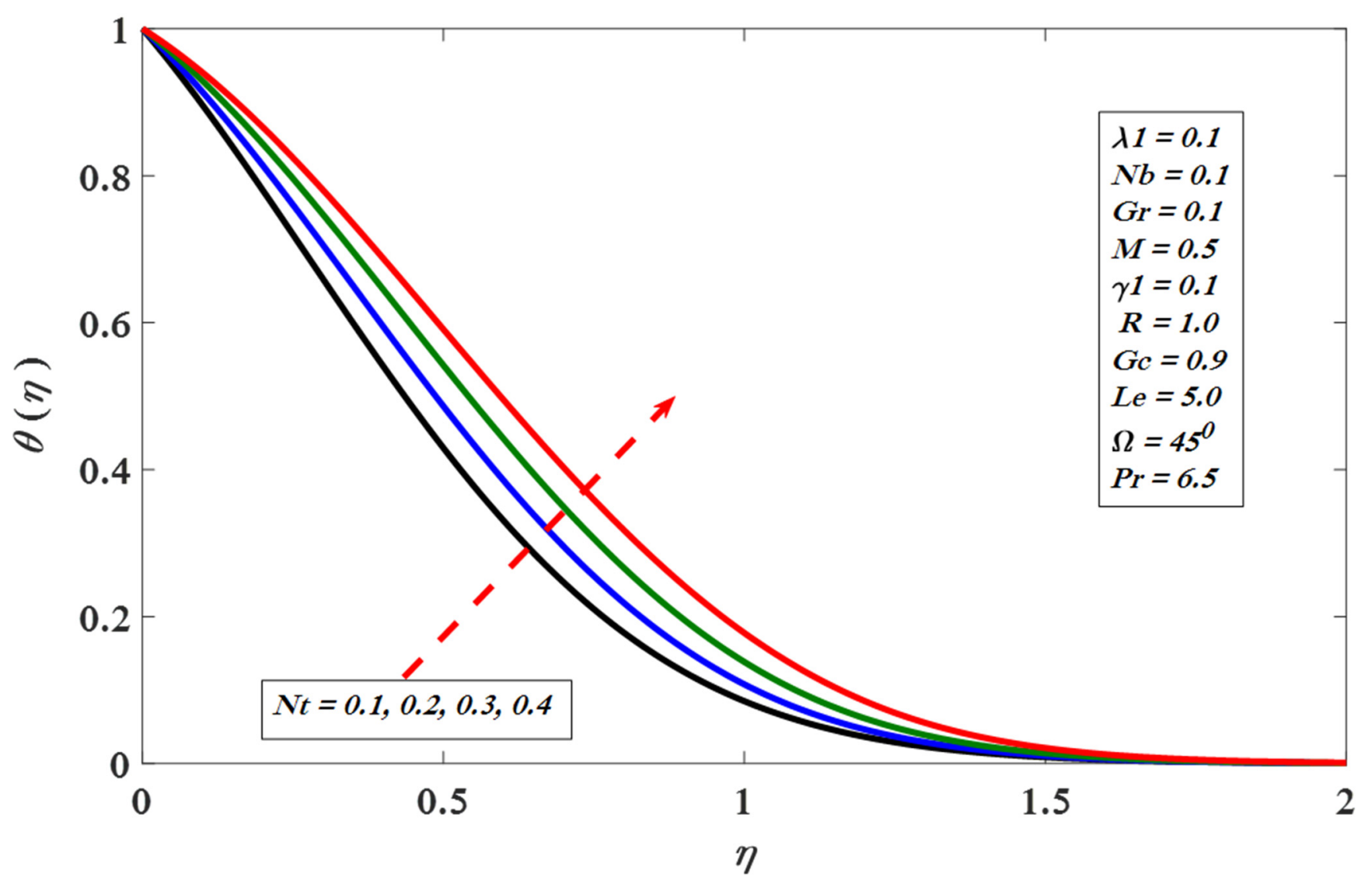

Figure 11. Temperature profile versus $N t$.

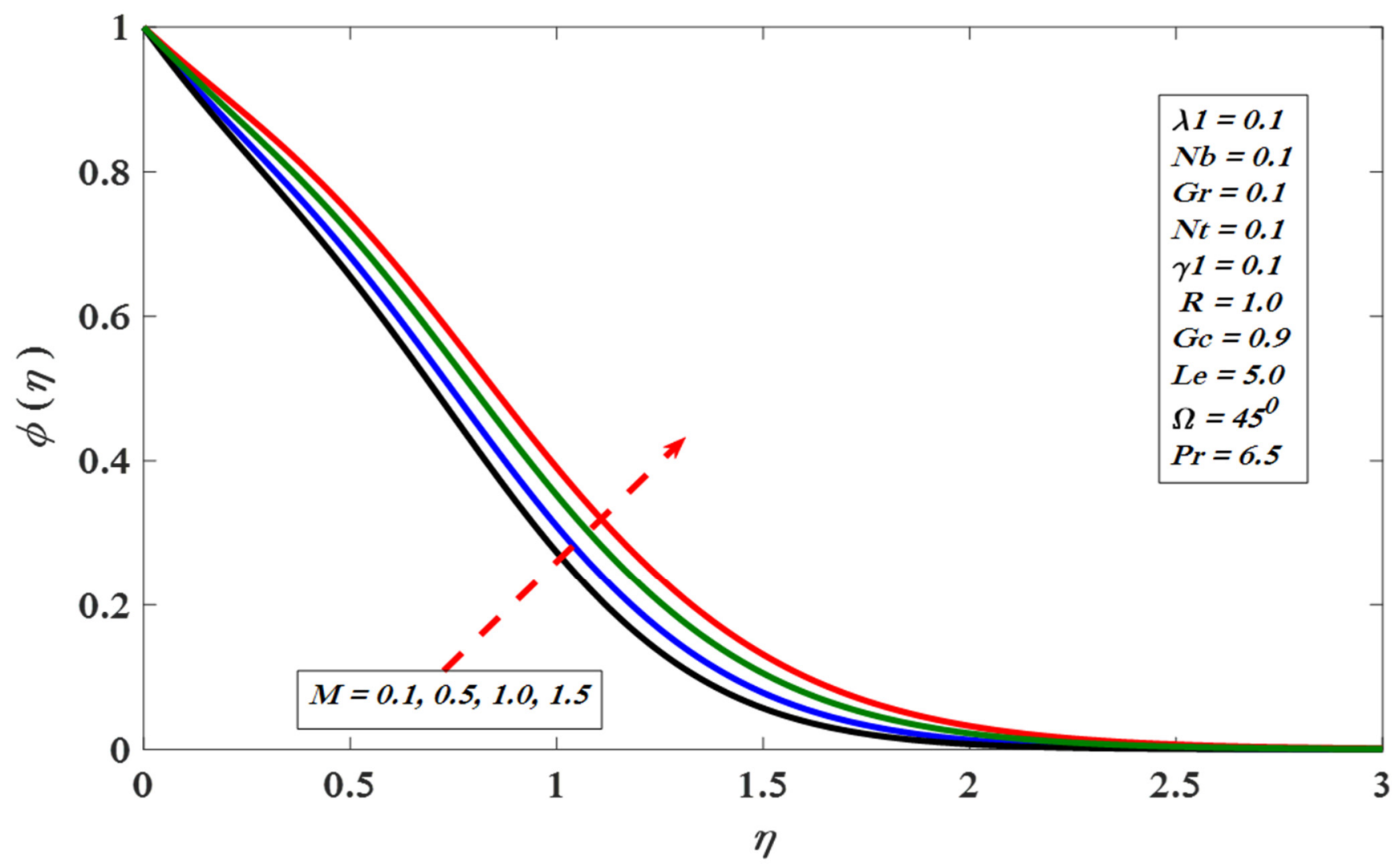

Figure 12. Concentration profile versus $M$. 


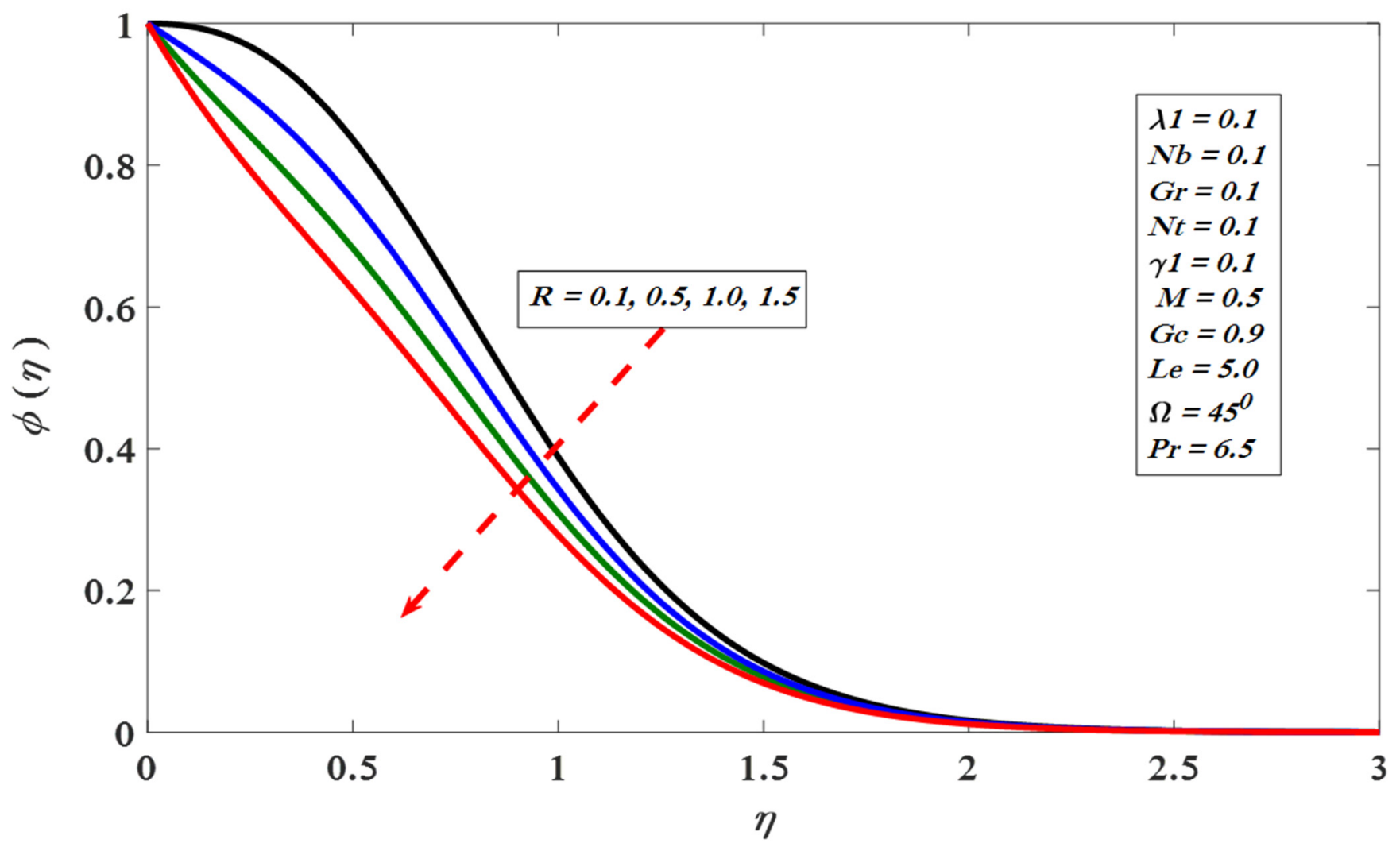

Figure 13. Concentration profile versus $R$.

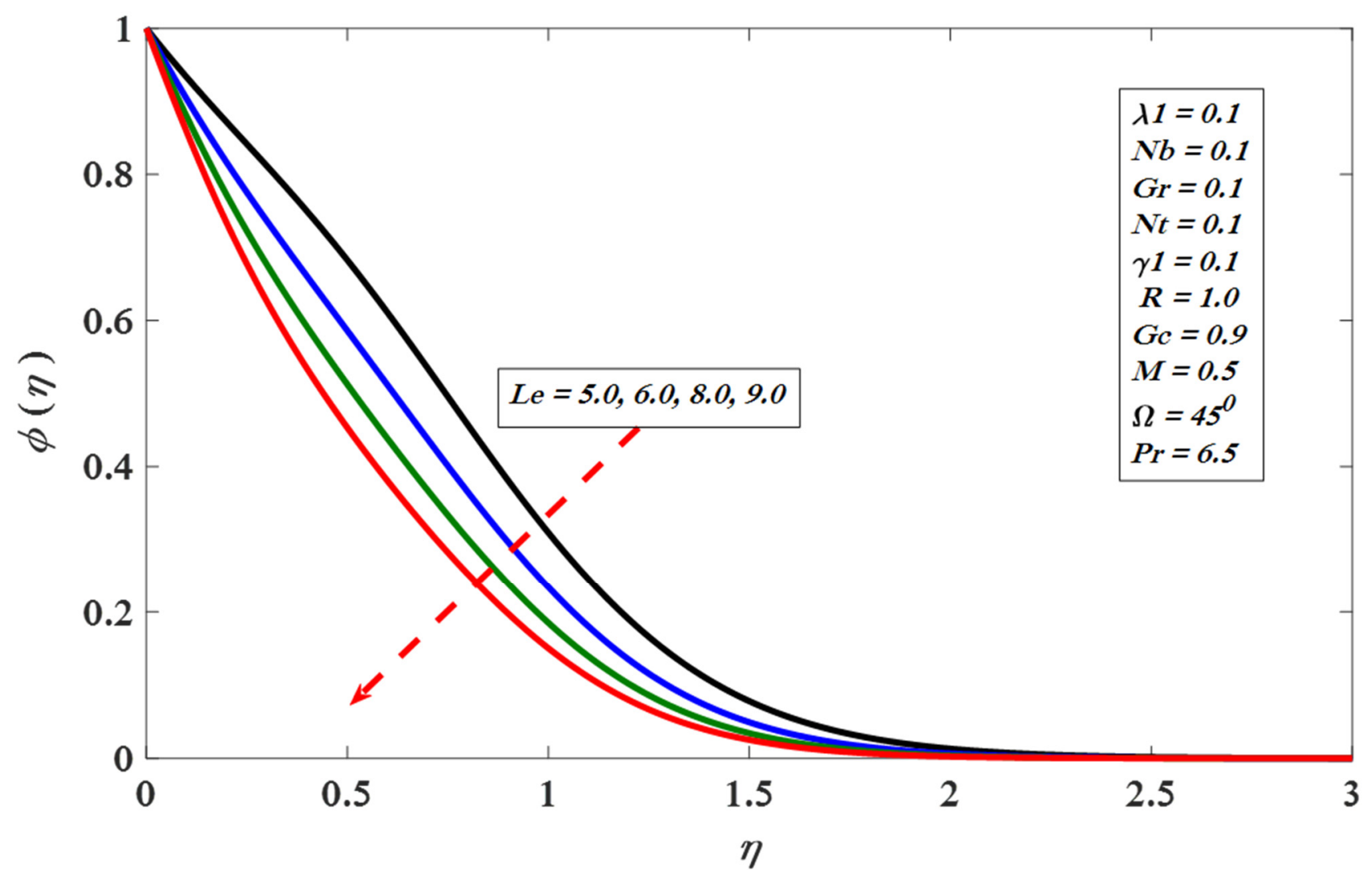

Figure 14. Concentration profile versus $L e$. 


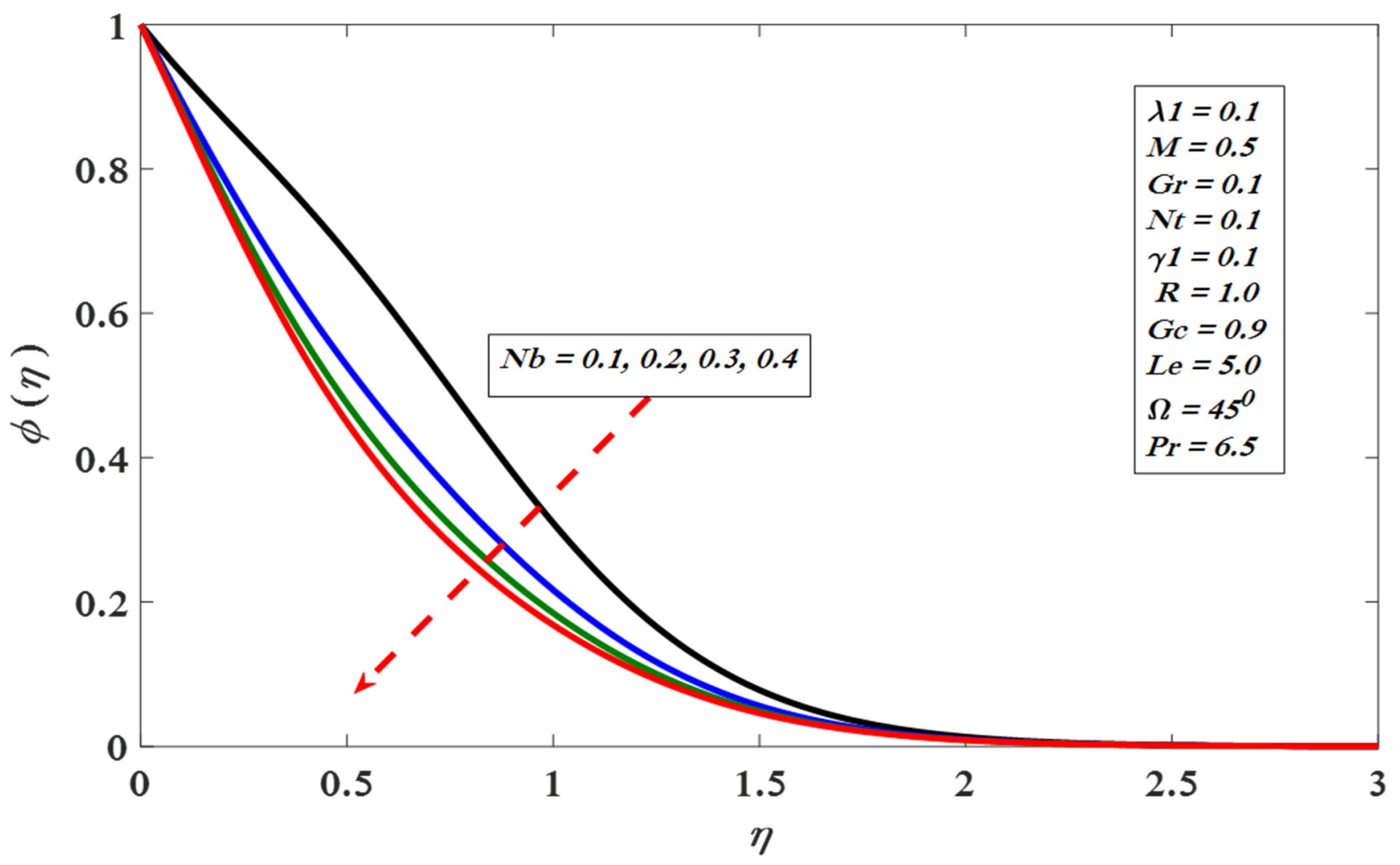

Figure 15. Concentration profile versus $N b$.

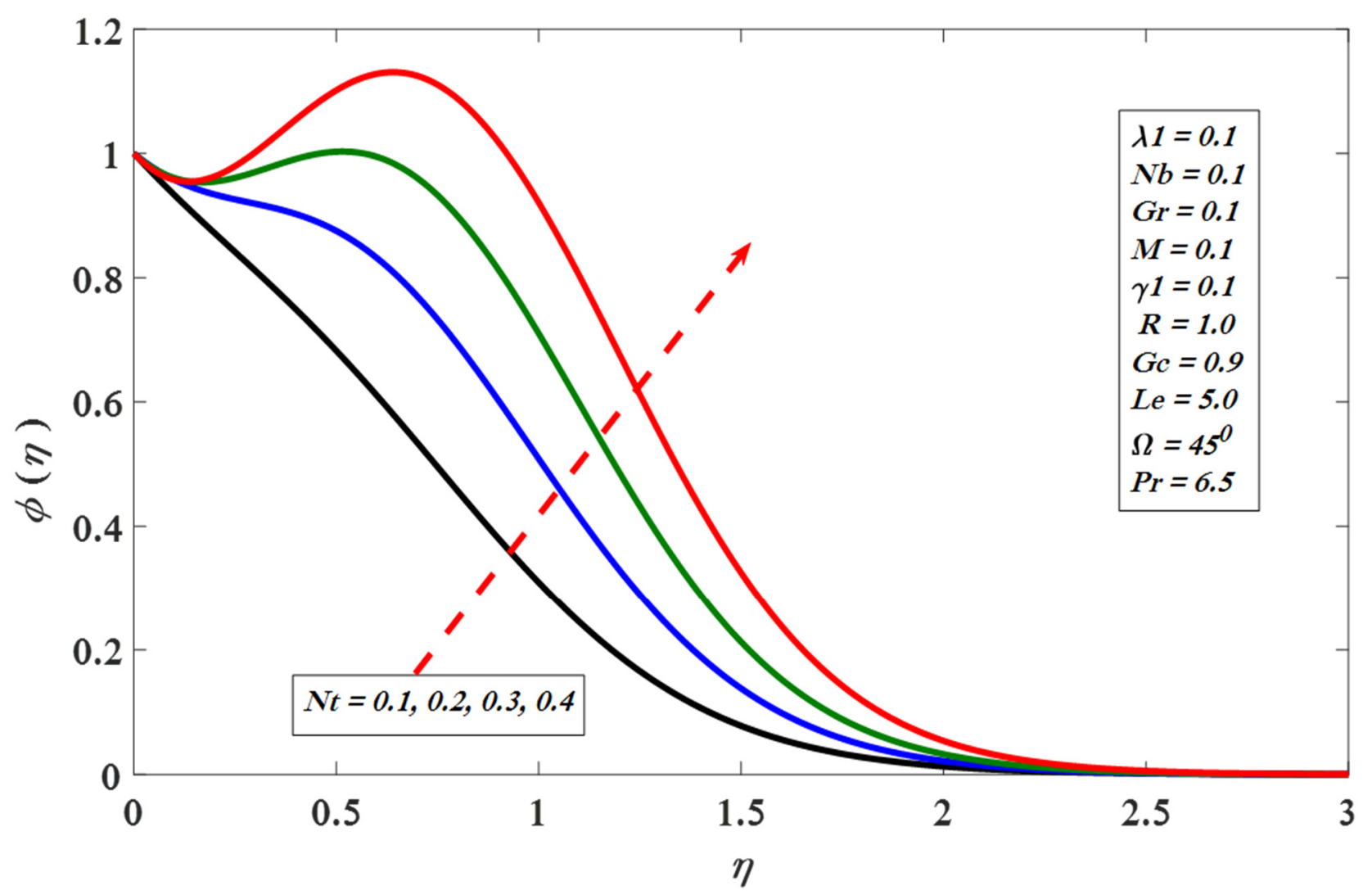

Figure 16. Concentration profile versus $\mathrm{Nt}$. 
The numerical computation represented in Table 1 shows that our results match the earlier results by Khan and Pop [35]. The behavior of skin friction, energy transfer rate, and species transport rate against various physical factors are exhibited in Table 2. Table 2 shows $-\theta^{\prime}(0)$ (energy transfer rate) decreases with distinct changes in $N b, M, \lambda_{1}, L e, N t, \gamma_{1}$, and $\Omega$, whereas it increases against $\operatorname{Pr}, G c, G r$, and $R$. Moreover, $-\phi^{\prime}(0)$ increases with changes in $N b, N t, L e, \lambda_{1}, G c, G r$, and $\gamma_{1}$ and decreases against the increasing $\operatorname{Pr}, R, M$, and $\gamma_{1}$. Additionally, $C_{f x}(0)$ increases with variations of $N b, L e, M, \lambda_{1}, \gamma_{1}, R$, and $\Omega$. In the same vein, $C_{f x}(0)$ shows an inverse effect against $N t, \operatorname{Pr}, G c, G r$. Table 3 presents a summary of the effects of the involved parameters on energy transfer rate, species transfer rate, and skin friction, in which an upward arrow sign indicates an increasing behavior, while a downward arrow sign indicates a decreasing behavior.

Table 1. Contrast of $M=1$, and $-\phi^{\prime}(0)$ against $M, R, \lambda_{1}, G r, G c, \gamma_{1}=0$ with $\operatorname{Pr}, L e=10$ and $\Omega=90^{\circ}$.

\begin{tabular}{cccccc}
\hline \multirow{2}{*}{$\mathbf{N b}$} & \multirow{N}{*}{$\boldsymbol{n}$} & \multicolumn{2}{c}{ Present Results } & \multicolumn{2}{c}{ Khan and Pop [35] } \\
\cline { 3 - 6 } & & $-\boldsymbol{\theta}^{\prime}(0)$ & $-\boldsymbol{\phi}^{\prime}(0)$ & $-\boldsymbol{\theta}^{\prime}(0)$ & $-\boldsymbol{\phi}^{\prime}(0)$ \\
\hline 0.1 & 0.1 & 0.9524 & 2.1294 & 0.9524 & 2.1294 \\
0.2 & 0.2 & 0.3654 & 2.5152 & 0.3654 & 2.5152 \\
0.3 & 0.3 & 0.1355 & 2.6088 & 0.1355 & 2.6088 \\
0.4 & 0.4 & 0.0495 & 2.6038 & 0.0495 & 2.6038 \\
0.5 & 0.5 & 0.0179 & 2.5731 & 0.0179 & 2.5731 \\
\hline
\end{tabular}

Table 2. Values of $-\theta^{\prime}(0),-\phi^{\prime}(0)$, and $C_{f x}(0)$.

\begin{tabular}{cccccccccccccc}
\hline $\boldsymbol{N b}$ & $\boldsymbol{N} \boldsymbol{t}$ & $\mathbf{P r}$ & $\boldsymbol{L} \boldsymbol{e}$ & $\boldsymbol{M}$ & $\boldsymbol{R}$ & $\boldsymbol{\lambda 1}$ & $\boldsymbol{G r}$ & $\boldsymbol{G} \boldsymbol{c}$ & $\gamma_{1}$ & $\boldsymbol{\Omega}$ & $-\boldsymbol{\theta}^{\prime}(\mathbf{0})$ & $-\boldsymbol{\phi}^{\prime}(\mathbf{0})$ & $\boldsymbol{C}_{f \boldsymbol{x}}(\mathbf{0})$ \\
\hline 0.1 & 0.1 & 6.5 & 5.0 & 0.3 & 1.0 & 0.1 & 0.1 & 0.9 & 0.1 & $45^{\circ}$ & 0.9850 & 0.7456 & 0.7823 \\
$\mathbf{0 . 4}$ & 0.1 & 6.5 & 5.0 & 0.3 & 1.0 & 0.1 & 0.1 & 0.9 & 0.1 & $45^{\circ}$ & 0.2400 & 1.2491 & 0.9576 \\
0.1 & $\mathbf{0 . 4}$ & 6.5 & 5.0 & 0.3 & 1.0 & 0.1 & 0.1 & 0.9 & 0.1 & $45^{\circ}$ & 0.5099 & 0.8885 & 0.8236 \\
0.1 & 0.1 & $\mathbf{1 0 . 0}$ & 5.0 & 0.3 & 1.0 & 0.1 & 0.1 & 0.9 & 0.1 & $45^{\circ}$ & 1.0210 & 0.7420 & 0.9891 \\
0.1 & 0.1 & 6.5 & $\mathbf{1 0 . 0}$ & 0.3 & 1.0 & 0.1 & 0.1 & 0.9 & 0.1 & $45^{\circ}$ & 0.8140 & 1.8849 & 0.9940 \\
0.1 & 0.1 & 6.5 & 5.0 & $\mathbf{0 . 5}$ & 1.0 & 0.1 & 0.1 & 0.9 & 0.1 & $45^{\circ}$ & 0.9657 & 0.7013 & 0.9881 \\
0.1 & 0.1 & 6.5 & 5.0 & 0.3 & $\mathbf{1 . 5}$ & 0.1 & 0.1 & 0.9 & 0.1 & $45^{\circ}$ & 1.0211 & 0.4417 & 0.7619 \\
0.1 & 0.1 & 6.5 & 5.0 & 0.3 & 1.0 & $\mathbf{0 . 3}$ & 0.1 & 0.9 & 0.1 & $45^{\circ}$ & 0.5569 & 1.0935 & 0.9076 \\
0.1 & 0.1 & 6.5 & 5.0 & 0.3 & 1.0 & 0.1 & $\mathbf{0 . 2}$ & 0.9 & 0.1 & $45^{\circ}$ & 0.9827 & 0.7459 & 0.8092 \\
0.1 & 0.1 & 6.5 & 5.0 & 0.3 & 1.0 & 0.1 & 0.1 & $\mathbf{1 . 3}$ & 0.1 & $45^{\circ}$ & 0.9947 & 0.7825 & 0.7019 \\
0.1 & 0.1 & 6.5 & 5.0 & 0.3 & 1.0 & 0.1 & 0.1 & 0.9 & $\mathbf{0 . 2}$ & $45^{\circ}$ & 0.9685 & 0.7499 & 1.0288 \\
0.1 & 0.1 & 6.5 & 5.0 & 0.3 & 1.0 & 0.1 & 0.1 & 0.9 & 0.1 & $\mathbf{6 0}$ & 0.9610 & 0.7143 & 1.0816 \\
\hline
\end{tabular}

Table 3. Summary of results for $-\theta^{\prime}(0),-\phi^{\prime}(0)$, and $C_{f x}(0)$.

\begin{tabular}{cccc}
\hline$N \boldsymbol{b}$ & $-\boldsymbol{\theta}^{\prime}(0)$ & $-\boldsymbol{\phi}^{\prime}(0)$ & $C_{f x}(0)$ \\
\hline$N b$ & $\downarrow$ & $\uparrow$ & $\uparrow$ \\
$N t$ & $\downarrow$ & $\uparrow$ & $\uparrow$ \\
$\operatorname{Pr}$ & $\uparrow$ & $\downarrow$ & $\uparrow$ \\
$L e$ & $\downarrow$ & $\uparrow$ & $\uparrow$ \\
$M$ & $\downarrow$ & $\downarrow$ & $\uparrow$ \\
$R$ & $\uparrow$ & $\downarrow$ & $\downarrow$ \\
$\lambda 1$ & $\downarrow$ & $\uparrow$ & $\uparrow$ \\
$G r$ & $\downarrow$ & $\uparrow$ & $\uparrow$ \\
$G c$ & $\uparrow$ & $\uparrow$ & $\downarrow$ \\
$\gamma_{1}$ & $\downarrow$ & $\uparrow$ & $\uparrow$ \\
$\Omega$ & $\downarrow$ & $\downarrow$ & $\uparrow$ \\
\hline
\end{tabular}

\section{Conclusions}

This study investigated the flow of Williamson nanofluid on an inclined surface. The numerical results were obtained by applying a numerical technique called the Keller 
box scheme. In this study, the magnetic field is taken perpendicular to the sheet. This research aims to develop and support the investigation of the Williamson nano fluid flow by considering inclined geometry. The important findings of the current analysis are:

- The Williamson parameter diminishes the velocity fluid in the flow field;

- The temperature profile reduces with the increase in chemical reaction effect;

- Heat and mass flux rates decrease with the increase in angle;

- Larger magnitudes of Williamson parameter improve both mass flux rate and wall shear stress;

- The inclination effect increment declines the velocity profile;

- Heat and mass exchange rate increase with the increment in local Grashof number;

- The velocity profile increases on improving the buoyancy force effect.

Future work could extend the analysis to different geometries, such as for disk, cylinder, cone, etc. Moreover, we could explore this study by incorporating different effects that are useful for engineering and industrial technologies.

Author Contributions: Conceptualization, K.R. and H.A.; methodology, K.R.; software, H.A.; validation, K.R. and H.A.; formal analysis, H.A.; investigation, K.R.; resources, K.R.; data curation, H.A.; writing —original draft preparation, K.R. and H.A.; writing—review and editing, K.R. and H.A.; visualization, K.R. and H.A. All authors have read and agreed to the published version of the manuscript.

Funding: This research received no external funding.

Acknowledgments: The authors are thankful for the Taif University research supporting project number (TURSP-2020/304), Taif University, Saudi Arabia.

Conflicts of Interest: The authors declare no conflict of interest.

\section{References}

1. Choi, S.U.S.; Eastman, J. Enhancing thermal conductivity of fluids with nanoparticles. ASME Publ. Fed. 1995, 231, 99-103.

2. Anwar, M.I.; Rafique, K.; Misiran, M.; Shehzad, S.A.; Ramesh, G.K. Keller-box analysis of inclination flow of magnetized Williamson nanofluid. SN Appl. Sci. 2020, 2, 377. [CrossRef]

3. Hayat, T.; Khan, M.; Khan, M.I.; Alsaedi, A.; Ayub, M. Electromagneto squeezing rotational flow of Carbon (C)-Water (H2O) kerosene oil nanofluid past a Riga plate: A numerical study. PLoS ONE 2017, 12, e0180976. [CrossRef]

4. Hayat, T.; Khan, S.A.; Khan, M.I.; Alsaedi, A. Optimizing the theoretical analysis of entropy generation in the flow of second grade nanofluid. Phys. Scr. 2019, 94, 085001. [CrossRef]

5. Waqas, M.; Khan, M.I.; Hayat, T.; Gulzar, M.M.; Alsaedi, A. Transportation of radiative energy in viscoelastic nanofluid considering buoyancy forces and convective conditions. Chaos Solitons Fractals 2020, 130, 109415. [CrossRef]

6. Khan, M.I.; Alsaedi, A.; Hayat, T.; Khan, N.B. Modeling and computational analysis of hybrid class nanomaterials subject to entropy generation. Comput. Methods Programs Biomed. 2019, 179, 104973. [CrossRef]

7. Anwar, M.I.; Rafique, K.; Misiran, M.; Khan, I. Numerical solution of casson nanofluid flow over a non-linear inclined surface with soret and dufour effects by keller-box method. Front. Phys. 2019, 7, 139.

8. Alotaibi, H.; Rafique, K. Numerical Analysis of Micro-Rotation Effect on Nanofluid Flow for Vertical Riga Plate. Crystals 2021, 11, 1315. [CrossRef]

9. Ghalambaz, M.; Doostani, A.; Izadpanahi, E.; Chamkha, A.J. Conjugate natural convection flow of $\mathrm{Ag}-\mathrm{MgO} / \mathrm{water}$ hybrid nanofluid in a square cavity. J. Therm. Anal. Calorim. 2020, 139, 2321-2336. [CrossRef]

10. Sheikholeslami, M.; Gerdroodbary, M.B.; Shafee, A.; Tlili, I. Hybrid nanoparticles dispersion into water inside a porous wavy tank involving magnetic force. J. Therm. Anal. Calorim. 2020, 141, 1993-1999. [CrossRef]

11. Bazdar, H.; Toghraie, D.; Pourfattah, F.; Akbari, O.A.; Nguyen, H.M.; Asadi, A. Numerical investigation of turbulent flow and heat transfer of nanofluid inside a wavy microchannel with different wavelengths. J. Therm. Anal. Calorim. 2020, 139, 2365-2380. [CrossRef]

12. Hussain, F.; Ellahi, R.; Zeeshan, A. Mathematical models of electro-magnetohydrodynamic multiphase flows synthesis with nano-sized hafnium particles. Appl. Sci. 2018, 8, 275. [CrossRef]

13. Ellahi, R.; Zeeshan, A.; Hussain, F.; Abbas, T. Thermally Charged MHD Bi-Phase Flow Coatings with Non-Newtonian Nanofluid and Hafnium Particles along Slippery Walls. Coatings 2019, 9, 300. [CrossRef]

14. Gorjaei, A.R.; Joda, F.; Khoshkhoo, R.H. Heat transfer and entropy generation of water-Fe3O4 nanofluid under magnetic field by Euler-Lagrange method. J. Therm. Anal. Calorim. 2019, 139, 2023-2034. [CrossRef]

15. Bohra, S. Heat and mass transfer over a three-dimensional inclined non-linear stretching sheet with convective boundary conditions. Indian J. Pure Appl. Phys. (IJPAP) 2017, 55, 847-856. 
16. Rafique, K.; Anwar, M.I.; Misiran, M. Keller-box Study on Casson Nano Fluid Flow over a Slanted Permeable Surface with Chemical Reaction. Asian Res. J. Math. 2019, 4, 1-17. [CrossRef]

17. Alotaibi, H.; Eid, M.R. Thermal Analysis of 3D Electromagnetic Radiative Nanofluid Flow with Suction/Blowing: DarcyForchheimer Scheme. Micromachines 2021, 12, 1395. [CrossRef]

18. Saqib, M.; Khan, I.; Shafie, S. Generalized magnetic blood flow in a cylindrical tube with magnetite dusty particles. J. Magn. Magn. Mater. 2019, 484, 490-496. [CrossRef]

19. Reddy, P.B.A. Magnetohydrodynamic flow of a Casson fluid over an exponentially inclined permeable stretching surface with thermal radiation and chemical reaction. Ain Shams Eng. J. 2016, 7, 593-602. [CrossRef]

20. Saqib, M.; Hanif, H.; Abdeljawad, T.; Khan, I.; Shafie, S.; Nisar, K.S. Heat Transfer in MHD Flow of Maxwell Fluid via Fractional Cattaneo-Friedrich Model: A Finite Difference Approach. Comput. Mater. Contin. 2020, 65, 1959-1973. [CrossRef]

21. Halim, N.A.; Sivasankaran, S.; Noor, N.F.M. Active and passive controls of the Williamson stagnation nanofluid flow over a stretching/shrinking surface. Neural Comput. Appl. 2016, 28, 1023-1033. [CrossRef]

22. Williamson, R.V. The Flow of Pseudoplastic Materials. Ind. Eng. Chem. 1929, 21, 1108-1111. [CrossRef]

23. Vijayalaxmi, T.; Shankar, B. Hydromagnetic flow and heat transfer of Williamson nanofluid over an inclined exponential stretching sheet in the presence of thermal radiation and chemical reaction with slip conditions. J. Nanofluids 2016, 5, 826-838. [CrossRef]

24. Khan, M.; Malik, M.; Salahuddin, T.; Hussian, A. Heat and mass transfer of Williamson nanofluid flow yield by an inclined Lorentz force over a nonlinear stretching sheet. Results Phys. 2018, 8, 862-868. [CrossRef]

25. Megahed, A.M. Williamson fluid flow due to a nonlinearly stretching sheet with viscous dissipation and thermal radiation. $J$. Egypt. Math. Soc. 2019, 27, 12. [CrossRef]

26. Bouslimi, J.; Omri, M.; Mohamed, R.A.; Mahmoud, K.H.; Abo-Dahab, S.M.; Soliman, M.S. MHD Williamson Nanofluid Flow over a Stretching Sheet through a Porous Medium under Effects of Joule Heating, Nonlinear Thermal Radiation, Heat Generation/Absorption, and Chemical Reaction. Adv. Math. Phys. 2021, 2021, 9950993. [CrossRef]

27. Gupta, S.; Kumar, D.; Singh, J. Analytical study for MHD flow of Williamson nanofluid with the effects of variable thickness, nonlinear thermal radiation and improved Fourier's and Fick's Laws. SN Appl. Sci. 2020, 2, 438. [CrossRef]

28. Rafique, K.; Anwar, M.I.; Misiran, M.; Khan, I.; Sherif, E.S.M. The implicit Keller Box scheme for combined heat and mass transfer of Brinkman-type micropolar nanofluid with Brownian motion and thermophoretic effect over an inclined surface. Appl. Sci. 2020, 10, 280. [CrossRef]

29. AlNemer, G.; Zakarya, M.; Abd El-Hamid, H.A.; Kenawy, M.R.; Rezk, H.M. Dynamic Hardy-type inequalities with non-conjugate parameters. Alex. Eng. J. 2020, 59, 4523-4532. [CrossRef]

30. AlNemer, G.; Zakarya, M.; Abd El-Hamid, H.A.; Agarwal, P.; Rezk, H.M. Some Dynamic Hilbert-Type Inequalities on Time Scales. Symmetry 2020, 12, 1410. [CrossRef]

31. Zakarya, M. Hypercomplex systems and non-Gaussian stochastic solutions of $\chi$-Wick-type (3+1)-dimensional modified BenjaminBona-Mahony equation. Therm. Sci. 2020, 24 (Suppl. 1), 209-223. [CrossRef]

32. Khater, M.; Abdel-Aty, A.H.; Alnemer, G.; Zakarya, M.; Lu, D. New optical explicit plethora of the resonant Schrodinger's equation via two recent computational schemes. Therm. Sci. 2020, 24 (Suppl. 1), 247-255. [CrossRef]

33. Nazar, R.; Amin, N.; Filip, D.; Pop, I. Stagnation point flow of a micropolar fluid towards a stretching sheet. Int. J. Non-Linear Mech. 2004, 39, 1227-1235. [CrossRef]

34. Nadeem, S.; Hussain, S.T. Flow and heat transfer analysis of Williamson nanofluid. Appl. Nanosci. 2014, 4, 1005-1012. [CrossRef]

35. Khan, W.A.; Pop, I. Boundary-layer flow of a nanofluid past a stretching sheet. Int. J. Heat Mass Transf. 2010, 53, 2477-2483. [CrossRef]

36. Rafique, K.; Anwar, M.I.; Misiran, M.; Khan, I.; Seikh, A.H.; Sherif, E.S.; Sooppy Nisar, K. Keller-Box Simulation for the Buongiorno Mathematical Model of Micropolar Nanofluid Flow over a Nonlinear Inclined Surface. Processes 2019, 7, 926. [CrossRef]

37. Rafique, K.; Anwar, M.I.; Misiran, M.; Asjad, M.I. Energy and mass transport of micropolar nanofluid flow over an inclined surface with Keller-Box simulation. Heat Transf. 2020, 49, 4592-4611. [CrossRef]

38. Rafique, K.; Anwar, M.I.; Misiran, M.; Khan, I.; Baleanu, D.; Nisar, K.S.; Sherif, E.-S.M.; Seikh, A.H. Hydromagnetic Flow of Micropolar Nanofluid. Symmetry 2020, 12, 251. [CrossRef]

39. Ramesh, G.K.; Gireesha, B.J.; Bagewadi, C.S. Heat Transfer in MHD Dusty Boundary Layer Flow over an Inclined Stretching Sheet with Non-Uniform Heat Source/Sink. Adv. Math. Phys. 2012, 2012, 657805. [CrossRef]

40. Ullah, I.; Khan, I.; Shafie, S. MHD natural convection flow of Casson nanofluid over nonlinearlystretching sheet through porous medium with chemical reaction and thermal radiation. Nanoscale Res. Lett. 2016, 11, 527. [CrossRef]

41. Salleh, S.N.A.; Bachok, N.; Arifin, N.M.; Ali, F.M. Numerical Analysis of Boundary Layer Flow Adjacent to a Thin Needle in Nanofluid with the Presence of Heat Source and Chemical Reaction. Symmetry 2019, 11, 543. [CrossRef] 